\title{
Indivíduo, liberdade e lazer na modernidade
}

\author{
LUIZ FLÁVIO NEUBERT \\ Doutorando em Sociologia (Universidade Federal de Minas Gerais) \\ Belo Horizonte, Brasil \\ luizfneubert@yahoo.com.br
}

\begin{abstract}
Resumo O fenômeno "individualidade" se desenvolveu de modo peculiar na modernidade, integrando um conjunto de transformações que iniciaram na Europa Medieval e, posteriormente, se expandiram por todas as culturas modernas. O lazer, como fato histórico, decorre também desse turbilhão de mudanças e está intimamente ligado ao ideal de liberdade que foi conferido ao indivíduo a partir do século XIX. O presente artigo tem como objetivo, pois, destacar o papel exercido pelo lazer em meio à busca moderna por liberdade para o indivíduo. Para tanto, pretende-se explorar dois conceitos elaborados por Georg Simmel e utilizá-los como guias para estabelecer uma relação entre Karl Marx, Sigmund Freud, Norbert Elias e Joffre Dumazedier.
\end{abstract}

Palavras-chave: indivíduo, sociedade, liberdade, modernidade, lazer.

\section{Introdução}

$\mathrm{O}$ FENÔMENO CONHECIDO COMO “INDIVIDUALIDADE" sofreu um desenvolvimento peculiar nos tempos modernos, sendo parte integrante das transformações que tiveram início na Europa Medieval e, posteriormente, se expandiram virtualmente por todas as culturas ocidentais. O lazer, como fato histórico, é também resultado desse turbilhão de mudanças e está intimamente ligado ao ideal de liberdade que foi conferido ao indivíduo a partir do século XIX.

A relação entre a construção simbólica da ideia de "indivíduo" e o ideal de liberdade, presentes na modernidade, foi alvo de investigações de Georg Simmel, em "O indivíduo e a liberdade" (2005). Além dele, Karl Marx e Sigmund Freud, outros importantes pensadores da civilização moderna, também se ocuparam da modernidade e de seus dilemas.

Simmel tem importância nesta discussão na medida em que analisa as principais matrizes histórico-sociais que formam a base da construção simbólica da ideia de indivíduo e dizem respeito, de forma mais geral, à valorização moderna de certo sentido de liberdade. O interesse por Marx se deve ao fato de sua teoria sobre o capitalismo permitir a percepção de como é especial o período histórico que se inicia a partir da Revolução Industrial. Esse momento excepcional da história humana apresenta novidades importantes, tais como o trabalho assalariado, o governo civil, os novos processos de produção, a luta entre as classes sociais, as formas de exploração etc.

Em relação a Freud, o interesse recai sobre a preocupação desse pensador com a constituição e a elaboração da personalidade no contexto da civilização burguesa moderna. Segundo Freud, o tipo de subjetividade que os indivíduos experimentam na civilização moderna depende de que sejam objeto de complexos processos de socialização cuja função é a de controlar os instintos e as predisposições internas, 
ao mesmo tempo em que se constrói a personalidade e se apreendem as estruturas simbólicas do mundo dos adultos. O que há de peculiar é o fato de que o indivíduo, ao fazer jus aos ditames da civilização, seja obrigado a rechaçar boa parte dos seus desejos e motivações, o que gera consequências para sua vida psíquica e social.

A primeira dupla de pensadores, Dumazedier e Elias, presta tributo a Marx e Freud, entre tantos outros que fogem ao propósito deste artigo. Interessa ressaltar, no entanto, que, para a segunda dupla de pensadores, modernidade e liberdade não se combinam, enquanto, para a primeira dupla, o lazer e as atividades recreativas representam o corolário de determinado sentido de liberdade que somente emergiu em tempos modernos.

De forma resumida, pode-se dizer que Elias, sob forte influência da teoria freudiana, trata dos costumes e dos comportamentos desenvolvidos ao longo do chamado "processo civilizador", no qual as atividades recreativas cumprem uma função importante para o equilíbrio ou ordem social. Por sua vez, Dumazedier "bebe" na fonte marxista ao elaborar a teoria na qual um dos eixos principais de desenvolvimento do lazer na modernidade é a inovação das forças produtivas que teve início com a Revolução Industrial no século XVIII. Ele também reconhece a importância que os movimentos sociais tiveram na liberação de homens, mulheres e jovens de muitas das obrigações institucionalizadas.

Este artigo tem como objetivo mais geral analisar a relação entre individualidade e lazer, destacando o papel exercido pelo lazer em meio à busca moderna por liberdade para o indivíduo. Para tanto, pretende-se explorar dois conceitos elaborados por Simmel e utilizá-los como guias para estabelecer uma relação entre, de um lado, Marx e Freud, e, de outro, as teorias que versam sobre surgimento do lazer na modernidade, desenvolvidas por Dumazedier e por Elias. Para atender ao objetivo proposto, as seções foram divididas como descrito a seguir: além desta introdução, as três próximas seções versam, separadamente, sobre os conceitos elaborados por Simmel e algumas ideias de Marx e Freud sobre a modernidade. A penúltima seção versa sobre as idéias de Elias e Dumazedier sobre o lazer e, por fim, a última seção é dedicada às considerações finais.

\section{Os tipos de individualidade}

Supõe-se que a individualidade teria surgido na Europa Ocidental na época do Renascimento italiano, como salienta Simmel (2005, p. 107), que a define como
[...] a superação tanto interna quanto externa do indivíduo das formas comunitárias medievais que conformavam a forma de vida, a atividade produtiva, os traços de caráter dentro de unidades niveladoras, fazendo desaparecer os traços pessoais e impossibilitando o desenvolvimento da liberdade pessoal, da singularidade própria de cada um e da auto-responsabilidade.

Era comum nas cortes da Idade Média o tipo "individualismo de distinção" (Simmel, 2005), que correspondia a uma disposição interna de se diferenciar pela aparência e de se tornar identificável, destoante dos outros. Somente no período histórico conhecido como Renascimento, datado entre os anos 1300 e 1650, ocorreu um movimento que buscou reviver a antiga cultura greco-romana, trazendo mudanças no campo das artes, da literatura e das ciências. O humanismo como ideal se tornou a principal fonte de inspiração. Significou uma busca consciente do passado como modelo para a construção de uma nova civilização baseada na revalorização do homem no seu sentido mais geral e abstrato, além de um olhar especial sobre a natureza através do uso da razão. Essa disposição se colocava em contraposição à cosmologia baseada na crença sobre a divindade e o sobrenatural, traços característicos da cultura da Idade Média.

A soma dessas pressões, segundo Simmel, teve como resultado o rompimento, no século XVIII, com a antiga noção de individualidade como distinção, que, por sua vez, foi substituída pela individualidade cujo mote principal era a ideia de liberdade. $\mathrm{O}$ produto desse movimento se tornou a principal forma pela qual os indivíduos dessa época se colocavam em relação à sociedade. Sua forma mais evidente foi explicitada na esfera econômica, na qual a livre concorrência entre interesses individuais em um mercado ideal tenderia a um equilíbrio de forças. A esse novo tipo de individualidade Simmel (2005) deu o nome de "individualidade quantitativa".

A concepção típica do Iluminismo - a de que a vida humana e a natureza eram regidas por leis cegas e impessoais, desprovidas de qualquer magia e passíveis de ser vislumbradas pelo uso da razão - mantinha uma relação estreita com a noção de homem genérico e abstrato. Os ideais pilares da Revolução Francesa foram corolários de tal visão sobre o indivíduo ao estabelecer como prioridade a liberdade e a igualdade, valores garantidos pelo direito e pela autorresponsabilidade.

Porém, as formas de vida próprias do século XVIII não permitiram que se levasse adiante o ideal de liberdade que cultivavam. Apesar de ser um período marcado por conquistas e superações, tanto do ponto de vista material quanto espiritual, ainda havia fortes limites impostos pelo contexto histórico e so- 
cial. Eram mantidos privilégios para certos grupos; o mercado sofria influências de certas corporações do comércio; a Igreja mantinha a intolerância e a repressão como formas de controle social; a população camponesa ainda vivia sob relações de servidão etc.

A igualdade que expressava a essência do homem abstrato não era a última etapa na luta pela liberdade, e isso se mostrou verdade durante o século XIX. Os indivíduos somente se sentiram impelidos a superar a igualdade e a buscar novamente a distinção quando esta surgiu como uma vontade interna. A ênfase não era mais sobre o indivíduo genérico, mas sim sobre a unicidade e peculiaridade de cada indivíduo concreto. Na modernidade que se consolida no século XIX, o sentido da vida individual é marcado por uma busca constante de si mesmo, por um núcleo inerte que tivesse a capacidade de garantir algum grau de solidez interna diante dos ditames do grupo social e das contingências históricas.

Essa elaboração se fez necessária na medida em que a vida moderna se tornava cada vez mais complexa e a busca de si mesmo se realizava internamente, e não externamente. Como consequência, cada indivíduo corresponde, desde então, a uma combinação única de forças que tem como resultado um ser especial e único. A esse fenômeno Simmel (2005) atribuiu o nome de "individualismo qualitativo".

\section{Liberdade e lutas de classes}

Se, para Simmel, a combinação entre certo ideal de liberdade e o conceito de indivíduo era um importante elemento no conjunto de inovações da modernidade, para Marx, isso não era tão venerável. Para ele, tudo não passava de uma consequência das relações de produção capitalista, as quais reclamavam para si um tipo de indivíduo egoísta, independente, racional, calculista etc. Segundo Marx (1996, p. 198), “a emancipação política é a redução do Homem, de uma parte, a membro da sociedade burguesa, a indivíduo egoísta independente [grifo meu]". Foram inúmeros os assaltos que Marx fez, por esse motivo, aos seus inimigos no sentido de "desmascarar" a ideologia burguesa, principalmente a que estava por trás da filosofia alemã de sua época. ${ }^{1}$

Ele reconhecia, porém, que a modernidade possuía traços peculiares e que o capitalismo surgido a partir da Revolução Industrial correspondia a um momento especial do processo histórico. Era a última etapa da luta de classes, momento em que as contradições entre infraestrutura e superestrutura se torna- vam as mais radicais, já que o capitalismo une a forma mais avançada dos modos de produção (indústria), até então conhecida, com a forma mais desigual de relação social de produção (a minoria de proprietários dos meios de produção e a maioria de proletariados vendedores da força de trabalho). ${ }^{2}$

A primeira dimensão, a do progresso científicotecnológico, no mundo utópico do pós-capitalismo, resultaria em benefícios para todos, e boa parte do trabalho relacionado à produção e reprodução da vida seria garantido com bem menos dificuldades. $\mathrm{O}$ indivíduo estaria livre dos limites impostos pela divisão social do trabalho e pelas relações de propriedade, que o impediam de gozar dos frutos da civilização moderna. Dessa forma, começaria a verdadeira história da humanidade, somente possível depois da superação das várias formas da luta de classes.

Mas, além de detectar os elementos ideológicos da cultura burguesa de sua época, Marx também reconhecia que certas mudanças ocorreram e poderiam ser consideradas como um progresso em relação à liberdade, mesmo que de forma imperfeita e inacabada. Isso se torna evidente quando, em seu pensamento, ele articula o estado avançado das forças produtivas e a liberdade do tipo burguesa, revelando, assim, sua verdadeira natureza:

A liberdade do egoísta e o reconhecimento dessa liberdade são, antes, o reconhecimento do movimento desenfreado dos elementos espirituais e materiais que formam seu conteúdo de vida. [...] Assim, o Homem não se viu libertado da religião; obteve, na verdade, a liberdade religiosa. Não se viu libertado da propriedade; obteve a liberdade de propriedade. Não se viu libertado do egoísmo da indústria; obteve a liberdade industrial. (Marx, 1996, p. 196)

Tais citações deixam claro que Marx não aceitava a ideia de que a modernidade capitalista resultaria em relações sociais mais justas e igualitárias. É exatamente o oposto disso que ele percebia. Por isso mesmo, o casamento entre capitalismo e liberdade não era uma verdade inconteste para o pensador em questão.

\section{Liberdade e civilização moderna}

Freud, assim como Marx, demonstrava ressalvas em relação à sociedade europeia civilizada de seu tempo. Segundo ele, dentre as três principais fontes do sofrimento humano, quais sejam a impotência 
diante da natureza, a fragilidade dos corpos e o ajuste às regras que condicionam as relações sociais entre os indivíduos (Freud, 1996, p. 93), a última é a que mais intriga. Tanto a natureza quanto nossos corpos (também parte da natureza) nos impõem limites que são insuperáveis (a morte, por exemplo). Mas, em relação aos ditames de uma sociedade altamente complexa e organizada, nossa reação é outra.

Segundo o fundador da psicanálise, boa parte da nossa angústia provém do fato de as regras que nós próprios criamos para possibilitar a convivência civilizada serem, também, causas do nosso sofrimento. E, o que é decerto trágico para Freud, quanto mais a civilização buscar se proteger das ameaças oriundas da natureza e do próprio mundo social, mais o próprio ideal de civilização será reforçado e valorizado.

A civilização, apreciadora da ordem, depende de um complexo processo social que tem como consequência o sacrifício dos instintos com a finalidade de garantir a organização e a existência do grupo social. Isso ocorre em detrimento da resistência individual e, muitas vezes, se direciona justamente contra ela. Se a balança sempre se desequilibrar para o lado da sociedade, e não houver nenhuma recompensa para o indivíduo diante de tantas renúncias, distúrbios psíquicos poderão surgir e acometer os mais entusiastas da civilização (Freud, 1996, p. 104).

A frustração do instinto sexual, por exemplo, poderia levar o indivíduo à neurose, quando este começasse a criar meios de substituir a satisfação reprimida, causando sofrimento em si próprio ou apresentando dificuldades de estabelecer e manter relacionamentos. Não só o impulso sexual, mas também os limites impostos ao impulso de agressividade e o processo de interiorização do sentimento de culpa são sacrifícios feitos em prol da manutenção do grupo social.

Tais argumentos apresentados justificam a afirmativa de Freud de que o homem não civilizado se achava em situação melhor quando não conhecia as restrições impostas aos instintos internos pela civilização. Segundo suas próprias palavras, "a liberdade do indivíduo não constitui um dom da civilização. Ela foi maior antes da existência de qualquer civilização, muito embora [...] dificilmente o indivíduo se achava em posição de defendê-la” (Freud, 1996, p. 102).

\section{Liberdade e lazer na modernidade ${ }^{3}$}

Diferentemente de Freud e Marx, e de certa forma alinhados de forma positiva com a concepção que relaciona a modernidade com a liberdade, alguns pensadores contemporâneos perceberam a importância de um fenômeno que atingiu pleno desenvolvimento na sociedade moderna e foi tratado e interpretado de diversas maneiras. $\mathrm{Na}$ obra Homo ludens: o jogo como elemento da cultura, por exemplo, Huizinga (1971) traçou o perfil cultural do jogo presente em grupos humanos e animais. $\mathrm{O}$ jogo corresponderia às atividades que possuem uma função significante que a distingue das outras atividades cotidianas.

Sua principal característica é o fato de ser uma "ilusão", pois permite a evasão da vida real através da prática de uma atividade que é um fim em si mesmo. Esta, por sua vez, se situa fora das satisfações imediatas da vida, tendo a função de afirmar a vida cotidiana na medida mesmo em que esta é negada durante um determinado período de tempo. É limitado e isolado no tempo e no espaço, pois possui uma teleologia própria em relação às demais atividades. Portanto, segundo essa concepção, o elemento lúdico representaria um momento especial na vida cotidiana rotineira. Pode-se dizer que ele permite a experiência de um mundo virtual, não querendo com isso fazer alguma referência às criações tecnológicas atuais. Conforme Simmel (1987, p. 11),

os problemas mais graves da vida moderna derivam da reivindicação que faz o indivíduo de preservar a autonomia e individualidade de sua existência em face das esmagadoras forças sociais, da herança histórica, da cultura externa e da técnica da vida.

Assim, por que não pensar que, talvez, a própria modernidade tenha criado as condições que permitem ao indivíduo uma saída, uma fuga, um período no tempo e no espaço para experiências inusitadas, realização de satisfações as mais diversas e para o desenvolvimento da própria subjetividade? Como dito acima, com base em Huizinga, o elemento lúdico incorporado em atividades recreativas, por exemplo, configura uma natureza diversa daquela das atividades ordinárias e rotineiras, necessárias e obrigatórias.

Seguindo essa mesma trilha, Dumazedier (1979) ressalta que o lazer é um fenômeno moderno, vinculado justamente à construção eminentemente moderna da ideia de "individualidade", um novo valor social traduzido por um novo direito social, qual seja o de o indivíduo dispor de um período determinado de tempo para a realização de atividades que visam à autossatisfação. Lazer é, portanto, o "conteúdo do tempo orientado para a realização da pessoa como fim último" (Dumazedier, 1979, p. 91). Ao contrário de autores que acreditam que o lazer esteve presente em outros momentos da história humana, Dumaze- 
dier defende que o tempo de trabalho e de não trabalho podem ser antigos, entretanto o lazer só surgiu efetivamente na civilização pós-Revolução Industrial (p. 26).

Nas sociedades pré-industriais (agrárias), o tempo de trabalho está diretamente condicionado pelos ciclos naturais e pelos períodos de pausa correspondente ao período de entressafra, ocupado com cerimônias, jogos etc. Este último não pode ser considerado o mesmo que o lazer como conhecemos hoje em dia porque não supõe o trabalho, mas sim a ausência (forçada) dele. Nessas sociedades, tanto o trabalho como o jogo e a festa estão diretamente ligados à ideia de comunidade, à celebração do mundo dos ancestrais e da tradição. Nesses contextos, a vida social não dá atenção especial ao indivíduo, mas sim ao grupo. ${ }^{4}$

Mas o desenvolvimento técnico-científico, relacionado principalmente à produção de mercadorias, atingiu um patamar relativamente único na Revolução Industrial, processo que se inicia no século XVIII e se estende ao século XIX. Como consequência, houve uma relativa regularização dos ciclos de trabalho e uma tendência à independência da produção com relação aos fenômenos naturais. ${ }^{5}$ Tais mudanças ligadas à produção e à divisão do trabalho ocorreram em um contexto urbanizado e de explosão demográfica, o que resultou em características singulares e em uma nova forma de organização social.

A ideia defendida pelos economistas do século XIX de que a acumulação de capital era necessária ao desenvolvimento econômico colaborou com a origem de uma moral do trabalho, herdeira de uma vertente do puritanismo protestante, como demonstrou Weber (2004), a qual impôs uma rígida jornada de trabalho em nome do progresso. O trabalho, definido como dever ligado à salvação dos crentes, negava o ócio tanto do ponto de vista econômico como moral. Este último incitava o consumo e podia levar ao vício e à delinquência, algo que em uma sociedade baseada na produção e no acúmulo não era visto com bons olhos (Sue, 1992, p. 20).

Em meio a esse processo, o tempo de trabalho passou a ser cronometrado, quantificado e transformado em mercadoria posta à venda em troca de salários (Thompson, 1998). Portanto, enquanto fonte de exploração, o trabalho passa a ter uma forte preponderância sobre a vida dos indivíduos, restando aos trabalhadores, fora do tempo de trabalho, apenas o tempo necessário para continuar sua jornada no dia seguinte.
Também se deve reconhecer o impacto que o desenvolvimento tecnológico teve em outras esferas da vida social que não o trabalho assalariado. $O$ desenvolvimento de equipamentos domésticos permitiu, principalmente à mulher, diminuir o tempo dedicado ao trabalho sem remuneração realizado no lar, por exemplo. Já os avanços das ciências médicas e farmacológicas possibilitaram a distribuição em massa de métodos seguros de contracepção, que permitiram o planejamento familiar unido a uma vida sexual ativa. Além disso, os avanços nessas mesmas áreas das ciências resultaram em um prolongamento da expectativa de vida das pessoas que, aliada ao advento da Previdência Social, produziu um fim de vida sem trabalho para os indivíduos de certa faixa etária (De Masi, 2001; Dumazedier, 1979).

Mas, se as mudanças na dimensão material da sociedade não garantiram o surgimento do lazer, que outro movimento influenciou esse processo? Além das transformações estruturais e econômicas, portanto, tiveram grande importância aquelas ocorridas na esfera cultural. Por exemplo, os movimentos operários do século XIX, que tiveram como consequência, dentre outras, a regulamentação das relações de trabalho e, posteriormente, a diminuição e definição oficial da jornada de trabalho.

Outros processos culturais também causaram mudanças nas diversas esferas da vida social, tais como a religião, a política e a família (Dumazedier, 1975). Essa é uma referência, por exemplo, ao processo de laicização e secularização das instituições, assim como às lutas contra os regimes de poder absolutistas e, posteriormente, contra os estados totalitários. Também podem ser citados os movimentos sociais que marcaram o século $\mathrm{XX}$, cujos principais atores foram os jovens e as mulheres, o que permitiu a liberação dos membros das famílias de várias obrigações que impunham fortes barreiras à escolha individual. Por fim, é importante ressaltar o surgimento das instituições pedagógicas que, desde então, cumprem parte da função de socialização, antes restrita ao grupo familiar.

O lazer é, portanto, resultado de dois movimentos, quais sejam:

a) Em primeiro lugar, ele é definido negativamente, tendo em vista a diminuição do tempo gasto com o trabalho profissional, com os cuidados com a família e com a casa, com as obrigações sociopolíticas e socioespirituais. Esse processo gerou uma porção de tempo livre da qual

4. Dumazedier utiliza-se da dicotomia durkheimiana (Durkheim, 1999), que já tinha como objeto de reflexão o "individualismo moral", instituição própria das sociedades nas quais predomina a solidariedade orgânica, em contraposição à solidariedade mecânica, própria das sociedades nas quais o grupo é a principal referência para seus membros.

5. Essa característica ainda inexiste em localidades rurais onde predomina a atividade agrícola, nas quais grande parte da produção industrial ainda depende dos ciclos naturais, não sendo, portanto, marcadas pela constância e regularidade (Aguiar, 1980). 
parte foi revertida em lazer do fim do dia, lazer do fim de semana, férias ou lazer do fim da vida (Dumazedier, 1979, p. 92).

b) Em segundo lugar, o tempo livre somente pôde ser transmutado em lazer quando parte dele foi dedicada exclusivamente às atividades que visam, prioritariamente, à satisfação do próprio indivíduo que as realiza. Um novo valor social havia transformado parte do tempo livre em um tempo que o indivíduo possuía, por direito, para libertar-se das obrigações institucionalizadas e dedicar-se a si mesmo. Não que a liberdade experimentada no lazer signifique anulação dos condicionamentos sociais, mas sim é a expressão da livre escolha do indivíduo, permitida em determinados período da vida cotidiana. Essa possibilidade de liberdade individual foi resultado, portanto, de mudanças econômicas, sociais e culturais, traduzidas no direito do indivíduo de dispor de um tempo para si mesmo (Dumazedier, 1975, 1979).

Assim, fica claro como Dumazedier articula o surgimento do lazer ao indivíduo e à ideia de liberdade. Elias também produz tal articulação, porém, através de um caminho um pouco diverso, como se pode ver a seguir.

Para Elias e Dunning (1992) o processo civilizador impõe ao indivíduo uma conformação psíquica que pode ser facilmente observada quando se comparam atitudes e comportamentos entre adultos e crianças. A exteriorização das emoções fortes, impulsos, desequilíbrios e paixões é tolerada entre as crianças, mas não entre os adultos. A herança freudiana no trabalho de Elias nos diz que o processo de socialização sofrido pela criança é marca fundamental da passagem da infância para a fase adulta, na qual as imposições e restrições aos impulsos internos atingem seu ápice. Entre os adultos, o autocontrole já se apresenta internalizado e automatizado nas atitudes e comportamentos cotidianos.

Nas sociedades tradicionais, as atividades religiosas, as festas e os rituais cumpriam o papel de educar os sentimentos e as emoções através da liberação das restrições e proibições sociais por um determinado espaço de tempo. Já nas sociedades industrializadas, altamente complexas e diferenciadas, a necessidade de organização e coordenação entre as atividades de vários indivíduos desconhecidos entre si levou à necessidade de maior autocontrole individual. A ampla interdependência das atividades entre indivíduos em um mesmo contexto social é garantida e mantida, segundo essa perspectiva, por um importante ator social, o Estado, guardião da ordem nas sociedades modernas.
Nesse contexto, as atividades recreativas ajudam a diminuir os efeitos nocivos da extrema rigidez que o autocontrole consciente e inconsciente impõe, recompensando os indivíduos com uma "regressão socialmente permitida" (Elias; Dunning, 1992, p. 145) ao comportamento infantil. Isso trouxe a possibilidade de o indivíduo adulto viver emoções e sentimentos característicos da vida das crianças, com o objetivo de equilibrar a balança entre as satisfações e as frustrações. As atividades recreativas, portanto, teriam a função de livrar os indivíduos da tensão causada pelo excesso de disciplina e controle, ideia muito próxima à referência feita a Huizinga e à função do elemento lúdico na cultura.

De acordo com esses pressupostos, podem-se distinguir as atividades diárias, como propõe Elias, quanto ao seu marco de referência, seja este os "outros" ou o próprio indivíduo. Em atividades como o trabalho profissional e os cuidados com a casa e a família, os outros são a referência principal para a realização da atividade; já as atividades recreativas têm como referencial o próprio indivíduo que as realiza.

Ao escolherem as atividades recreativas, os indivíduos levam em conta, principalmente, o prazer e a satisfação dentro dos limites aceitos pela coletividade. Elas cumprem uma "função des-rotinizante" (Elias; Dunning, 1992, p. 135), em contraste com as atividades que comportam graus variados de "rotinização". As rotinas carregam em si um alto grau de segurança, previsibilidade etc. As atividades recreativas têm como função, portanto, introduzir na vida dos indivíduos certos momentos de insegurança, de tensão (como no jogo) e de liberação das emoções, tornando suportável a realização das atividades altamente rotinizadas.

\section{Considerações finais}

Apesar de percorrerem caminhos diversos, Elias e Dumazedier chegam a conclusões próximas quando identificam o caráter libertário que o lazer expressa em vista das obrigações, restrições e limitações impostas pela organização social, pela divisão do trabalho e pelas instituições de poder. Ambos têm como pressuposto que as atividades de lazer incorporam um elemento funcional na relação entre o indivíduo e a sociedade moderna, uma forma inovadora que a primeira parte dispõe para satisfazer desejos, elaborar conteúdos subjetivos, cuidar do corpo, buscar equilíbrio emocional, estreitar laços de amizade ou de intimidade etc.

A sociedade moderna, civilizada e burguesa, composta, portanto, por indivíduos (no sentido aqui discutido), cria situações especiais, nas quais estes úl- 
timos podem desenvolver atividades criativas (e produtivas) fora de relações sociais de produção e reprodução do capital. Além disso, mesmo que o indivíduo sofra dos constrangimentos que são a base da formação da personalidade adulta, existe a possibilidade de, durante certos períodos de tempo, realizar atividades que carregam, em seu conteúdo simbólico, um sentido de nostalgia em relação à infância. Também é parte disso o sentido lúdico que certas atividades engendram, pois elas criam situações extracotidianas, que se opõem de forma radical à segurança e certeza das atividades cotidianas ordinárias.

O momento na história humana ao qual chamamos de "modernidade", e do qual os pensadores aqui relacionados são interpretes de grande influência, é constituído de múltiplas facetas, inclusive contraditórias entre si. ${ }^{6}$ Estas, por sua vez, se revelam conforme os pressupostos teóricos e conceituais com os quais o investigador projeta um olhar interpretativo, parcial e seletivo, como concordaria Weber.

As constatações de que os indivíduos na modernidade se libertaram de várias restrições impostas pela tradição e pelo grupo social (ou que vivem integrados a regimes políticos mais justos e democráticos, que conseguiram aumentar relativamente o nível de controle sobre as intempéries da natureza através do desenvolvimento técnico-científico e ultrapassaram as barreiras impostas pelo corpo, criando novas formas de se deslocar, comunicar etc.) não estão necessariamente em contradição com outras constatações (por exemplo, a de que os indivíduos mantêm um grande esquema colaborativo sob forte influência de restrições, imposições e boa dose de disciplina).

Há mudanças substantivas entre as novas e velhas formas de liberdade, ao mesmo tempo em que são criadas novas formas de controle sobre os indivíduos, muito diversas das anteriores. E como liberdade e limites convivem de uma forma única na realidade empírica, portanto, um esforço intelectual se faz importante no sentido de ser capaz de revelar todos esses elementos, separá-los e, posteriormente, relacioná-los.

Ao apostar na criatividade humana, Simmel nos lembra que as mudanças sociais caminham, lado a lado, com limitações e chances de superação. Em relação às limitações que a sociedade moderna impôs, analisadas por Marx e Freud, os indivíduos foram capazes de exercer resistência e elaborar formas de assegurar a liberdade, como propõem Elias e Dumazedier. Mas isso não significa que as restrições à liberdade tenham sido superadas de uma vez por todas. $O$ indivíduo vive um jogo paradoxal, no qual cria formas de se libertar diante da realidade que ele mesmo colabora para construir e reproduzir, mas contra a qual ele também deve oferecer certo grau de resistência. ${ }^{7}$ Isso nos remete às últimas palavras de Simmel em O indivíduo e a liberdade:

Prefiro acreditar, no entanto, que a idéia da mera personalidade livre e da mera personalidade singular não sejam ainda as últimas palavras do individualismo. Ao contrário, a esperança é que o imprevisível trabalho da humanidade produza sempre mais, e sempre mais variadas formas de afirmação da personalidade e do valor da existência. E que, quando em períodos felizes, essas variedades consigam chegar a formar conjunções harmônicas, suas contradições e lutas não sejam vistas apenas como obstáculo, mas sim como potenciais para o desenvolvimento de novas forças e criações. (Simmel, 2005, p. 115)

O período do qual Simmel trata em seus estudos corresponde ao que Riesmann, Glazer e Denney $(1971)^{8}$ identificam como a primeira revolução moderna, que começa com a Renascença, passa pela Reforma, pela Contrarreforma, pela Revolução Industrial e pelas revoluções políticas dos séculos XVII, XVIII, XIX. Ela corresponde à era da produção, ${ }^{9}$ em que impera o tipo "introdirigido", voltado para o trabalho anônimo e para a elaboração interna de si mesmo. Esse

6. Peter Wagner (1994), por exemplo, é sensível ao fato de que uma análise mais acurada da modernidade depende da distinção entre o discurso sobre o projeto moderno de sociedade e as próprias práticas e instituições modernas. No plano do discurso, é possível destacar dois tipos de narrativas: o discurso da liberdade e o discurso da disciplina.

7. Segundo Simmel (1973, p. 131), "a liberdade emerge como um processo contínuo de liberação, como lutar por nossa independência, pelo direito de escolhermos a qualquer momento e por livre vontade, ainda que nossa escolha recaia sobre o permanecermos dependentes". Essa interpretação dá conta do caráter complexo da liberdade propiciada pelo lazer. O indivíduo se lança contra a opressão externa sem querer, com isso, aniquilá-la. Procura, isso sim, transformá-la ou moldá-la, buscando conforto e satisfação.

8. Como é claro para o leitor familiarizado com as ideias de Simmel, a relação entre densidade demográfica de um grupo e o correlato tipo psicológico dos indivíduos que o compõem é seu principal tema em A metrópole e a vida mental (1987). Seguindo essa mesma trilha, Riesmann, Glazer e Denney (1971) elaboraram uma análise do tipo de "caráter social" predominante nas sociedades ocidentais avançadas, tendo como pressuposto que as características demográficas de um grupo produzem nos indivíduos mecanismos psicológicos que garantem algum grau de conformidade. Como as características demográficas de um grupo variam de acordo com o tempo, das épocas históricas podemos deduzir um tipo de caráter social predominante e, consequentemente, um tipo de mecanismo psicológico.

9. Ou o que Zygmunt Bauman (2001) chamou de "modernidade pesada" ou "modernidade sólida". 
tipo colabora para a relação histórica entre liberdade e lazer na medida em que distingue claramente as esferas do trabalho e da diversão, apesar de a segunda ser sempre secundária em ordem de importância.

Riesmann, Glazer e Denney (1971) falam de uma segunda revolução, ocorrida no século XX. ${ }^{10}$ Correspondente à era do consumo e da oferta de serviços, na qual impera o tipo "alterdirigido". Esse tipo possui a mentalidade voltada para as pessoas, mantidas em relação por variados meios de comunicação de massa. Nesse contexto, a distinção entre trabalho e lazer se torna difusa, pois o mundo dos negócios é invadido por atitudes típicas da esfera do consumo e do divertimento.

Isso nos leva a crer que Simmel tinha razão ao dizer que a relação entre indivíduo (e, como foi de- fendido aqui, o lazer) e liberdade ainda não tinha chegado à sua última forma, aquela da personalidade livre e singular.

\section{Agradecimentos}

À Fundação de Amparo à Pesquisa do Estado de Minas Gerais (FAPEMIG) por apoiar a elaboração e a apresentação deste artigo no XIV Congresso Brasileiro de Sociologia, ocorrido na cidade do Rio de Janeiro em julho de 2009. Agradecimento especial a Neuma F. de Aguiar, Márcio F. de Souza, Arnaldo Mont'Alvão e aos pareceristas pelas críticas e sugestões.

10. Seguindo a dicotomia de Bauman (2001), esta seria a "modernidade leve" ou "modernidade líquida", quando, dentre outras coisas e por uma série de motivos, as fronteiras entre as esferas da vida se tornam pouco nítidas.

\section{Referências}

AGUIAR, Neuma Figueiredo. Tempo de transformação no nordeste. Petrópolis: Vozes, 1980.

BAUMAN, Zygmunt. Modernidade líquida. Rio de Janeiro: Jorge Zahar, 2001.

DE MASI, Domenico (Comp.) A economia do ócio. Rio de Janeiro: Sextante, 2001.

DUMAZEDIER, Joffre. Questionamento teórico do lazer. Porto Alegre: Perspectiva, 1975.

1979.

Sociologia empírica do lazer. São Paulo: Perspectiva,

DURKHEIM, Emile. Da divisão do trabalho social. São Paulo: Martins Fontes, 1999.

ELIAS, Norbert; DUNNIG, Eric. El ocio en el espectro del tiempo libre. In: Deporte y ocio en el processo de la civilización. Madrid: Fondo de Cultura Económica, 1992. p. 117-156.

ELIAS, Nobert. A sociedade dos indivíduos. Rio de Janeiro: Jorge Zahar, 1994.

FREUD, Sigmund. O mal-estar na civilização. In: Obras psicológicas completas de Sigmund Freud: edição standard brasileira. Rio de Janeiro: Imago, 1996. p. 73-148.

HUIZINGA, Johan. Homo ludens: o jogo como elemento da cultura. São Paulo: Perspectiva, 1971.

MARX, Karl. O cidadão. In: IANNI, Octavio (Org.). Karl Marx. São Paulo: Ática, 1996. (Grandes Cientistas Sociais, 10).
MARX, Karl; ENGELS, Friedrich. Manifesto do Partido Comunista. Rio de Janeiro: Cátedra, 1985.

A ideologia alemã. São Paulo: Martins Fontes, 2002.

RIESMAN, David; GLAZER, Nathan; DENNEY, Reuel. A multidão solitária: um estudo da mudança do caráter americano. São Paulo: Perspectiva, 1971.

SIMMEL, Georg. O indivíduo e a liberdade. In. SOUZA, J.; OELZE, B. (Org.). Simmel e a modernidade. 2. ed. Brasília: Ed. UnB, 2005. p. 107-115.

A metrópole e a vida mental. In: VELHO, G. (Org.). O fenômeno urbano. Rio de Janeiro: Jorge Zahar., 1987. p. 11-25.

O indivíduo e a díade. In: CARDOSO, F. H.;

IANNI, O. (Org.). Homem e sociedade. São Paulo: Companhia Ed. Nacional, 1973. p. 128-135.

SUE, Roger. El ocio. México: Fondo de Cultura Económica, 1992.

THOMPSON, Edward P. Tempo, disciplina de trabalho e o capitalismo industrial. In: Costumes em comum. São Paulo: Companhia das Letras, 1998. p. 267-304.

WAGNER, Peter. A sociology of modernity: liberty and discipline. London: Routledge, 1994.

WEBER, Max. A ética protestante e o espirito capitalista. São Paulo: Companhia das Letras, 2004. 


\title{
Individual, freedom and leisure in the modernity
}

\begin{abstract}
The phenomenon known as "individuality" has been through peculiar changes in modern time. It is part of a group of changes that started in Medieval Europe and that have expanded virtually to all modern cultures. Leisure, as a historical fact, also results from this boost of changes and is closely related to the idea of freedom that was adopted by individuals after the $19^{\text {th }}$ century. This article aims at pointing out the role of leisure in the pursuit of individual freedom. To do so, two concepts elaborated by Simmel will be explored and used as guidelines to establish a relationship between Karl Marx, Sigmund Freud, Nobert Elias and Joffre Dumazedier.
\end{abstract}

Key words: individual, society, freedom, modernity, leisure.

\section{Individuo, libertad y ocio en modernidad}

\section{Resumen}

El fenómeno sabido como "individualidad" tiene un desarrollo peculiar en modernidad, siendo parte de un conjunto de transformaciones que se inician en la Europa medieval y que, más adelante, se habían ampliado para todas las culturas modernas. El ocio, como hecho histórico, también se resulta de este remolino de cambios y está de cerca encendido a la libertad ideal que fue conferida al individuo a partir del siglo XIX. Este artículo pretende, por tanto, resaltar el papel desempeñado por medio de ocio de la búsqueda moderna de la libertad para el individuo. Para de tal manera, se piensa para explorar dos conceptos desarrollados por Simmel y utilizarlos como guías para establecer una relación entre Karl Marx, Sigmund Freud, Norbert Elias y Joffre Dumazedier.

Palabras clave: individual, sociedad, libertad, modernidad, ocio.

Data de recebimento do artigo: 12/4/2010

Data de aprovação do artigo: 30/7/2010 